\title{
OBTENÇÃO E CARACTERIZAÇÃO DE FILMES POLIMÉRICOS ULTRAFINOS AUTOMONTADOS COM VIOLETA CRISTAL
}

\section{OBTATION AND CHARACTERIZATION OF AUTOMATED ULTRATHIN POLYMER FILMS WITH CRYSTAL VIOLET}

\author{
Fernanda Rechotnek, Bruno Claudino dos Santos, Adriano Lopes \\ Romero, Rafaelle Bonzanini Romero. \\ Departamento Acadêmico de Química, Universidade Tecnológica Federal do \\ Paraná, Campo Mourão, Paraná. \\ e-mail: fernandarctk@hotmail.com.
}

\begin{abstract}
RESUMO - Para a obtenção dos filmes utilizou-se o método da deposição por automontagem, camada por camada, em que substâncias catiônicas e aniônicas são depositadas em um substrato a fim de formar uma dupla camada elétrica, ou seja, uma bicamada. Conforme as bicamadas são depositadas forma-se um filme. $\mathrm{O}$ intuito foi analisar a interação do polímero poli(vinil álcool) com cristal violeta e compará-lo com o filme de carboximetilcelulose com violeta cristal. Para a obtenção e análise dos resultados utilizou-se, o espectro de absorção e a curva de crescimento dos filmes, onde comprovou-se a interação do polímero poli(vinil álcool) com violeta cristal, assumindo caráter aniônico.

Palavras-chave: filmes automontados; polímeros; técnica camada por camada; sensores eletroquímicos.
\end{abstract}

Recebido em: $16 / 08 / 2017$

Revisado em: 18/09/2017

Aprovado em: 23/09/2017
ABSTRACT - To obtain the films, the self-assembling method was used, layer by layer, in which cationic and anionic substances are deposited in a substrate in order to form a double electric layer, that is, a bilayer. As the bilayers are deposited a film is formed. The aim of this study was to analyze the interaction of the poly (vinyl alcohol) polymer with violet crystal and to compare it with the carboxymethylcellulose film with crystal violet. In order to obtain and analyze the results, we used the absorption spectrum and the growth curve of the films, where the interaction of the poly (vinyl alcohol) polymer with crystal violet was confirmed, assuming an anionic character.

Keywords: self-made films; polymers; layer-by-layer technique; electrochemical sensors. 


\section{INTRODUÇÃO}

Entre as técnicas utilizadas para a obtenção dos filmes, a automontagem, também conhecida como LbL (do inglês "Layer-by-Layer") que significa deposição camada por camada, é um método que possibilita a produção de filmes ultrafinos organizados em um nível nanométrico, por meio de diferentes tipos de materiais, de maneira simples e de baixo custo, podendo ser feita a aplicação manualmente (GREGORUT, 2012; PATERNO; MATTOSO; OLIVEIRA JR., 2001).

\section{A técnica consiste na deposição} alternada de policátions e poliânions em um substrato sólido, sem a necessidade de intervenção externa, pois a autodeposição ocorre com caráter espontâneo (LIMA, 2014; VOLPATI, 2012; ALMEIDA, 2012), de modo que forma-se uma dupla camada elétrica, consequentemente, com as repetições temse a formação de filmes poliméricos.

Esse trabalho consiste no estudo de filmes poliméricos ultrafinos, depositados pela técnica de automontagem, ou seja, deposição camada por camada (Layer-byLayer) por meio da interação eletrostática para a utilização em sensores do tipo língua eletrônica. O intuito do trabalho é analisar a interação do polímero poli (álcool vinil) (PVA) com o composto violeta cristal e compará-lo com o filme de carboximetilcelulose de sódio (CMC) com violeta cristal.

\section{METODOLOGIA}

Para verificar a influência da espessura das camadas do polímero poli(álcool vinil) (PVA) na obtenção dos filmes preparou-se duas concentrações, sendo 10 e 40 mg.mL-1, enquanto o polímero carboximetilcelulose de sódio (CMC) foi preparado na concentração $10 \mathrm{mg} \cdot \mathrm{mL}-1$. Os filmes automontados foram preparados por deposição camada por camada de polieletrólitos catiônico e aniônico (como esquematizado na Figura 1), unidos por interação eletrostática entre si. Inicialmente, imergiu-se o substrato (placa de vidro) na solução aquosa contendo o polímero, podendo ser PVA ou CMC, deixando por 3 minutos. Em seguida, fez-se a lavagem em água, com intuito de se retirar o excesso de polímero não depositado, e deixou secar ao ar. Sobre a camada do polímero, uma camada do composto violeta cristal (VIO) foi depositada por imersão do substrato em uma solução aquosa de $\mathrm{VIO}$, durante 3 minutos. Lavou-se com água por 2 minutos e deixou secar. 
Figura 1. Representação esquemática do processo de automontagem de uma bicamada.

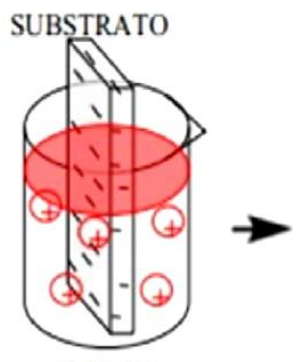

Policátion

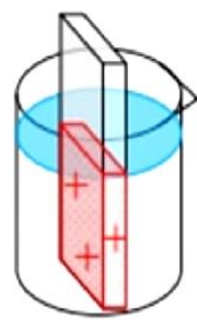

Soluçăo de lavagem

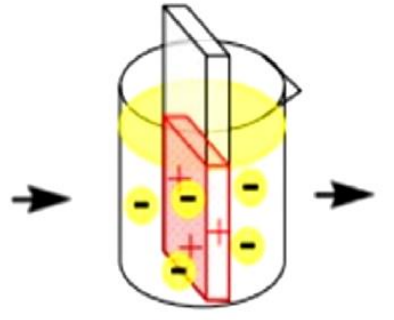

Poliaanion

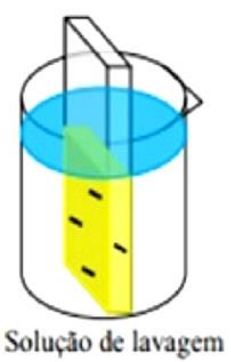

Fonte: Adaptado de DANTAS (2009, p.30).

A cada deposição das bicamadas, o crescimento e deposição das camadas, foram analisados em um espectrofotômetro UV-Vis T70+, PG Instruments. Estas etapas foram repetidas 9 vezes, totalizando 10 bicamadas, e portanto, tendo-se um filme automontado.

\section{RESULTADOS}

O polímero poli(vinil álcool) obteve bons resultado com o composto violeta cristal, apresentando um filme homogêneo e sem manchas (Figura 2), sendo assim, as Figuras 3 e 5 apresentam os gráficos dos espectros de absorção de PVA1/VIO e PVA4/VIO, respectivamente.
Na Figura 4 é apresentada a curva de crescimento do filme PVA1/VIO nos comprimentos de onda de 571 e 603, com coeficientes de correlação de 0,98398 e 0,98546, respectivamente. A Figura 6 apresenta a curva de crescimento do filme de PVA4/VIO com absorbância máxima em 565 e $603 \mathrm{~nm}$, apresentando coeficiente de correlação de 0,94486 e 0,95382, respectivamente. Sendo assim, entre os filmes de PVA depositados na superfície do vidro com o composto violeta cristal o melhor crescimento foi do filme de PVA1/VIO.

Figura 2. Imagens de Microscopia óptica dos filmes de (a) PVA1 e (b) PVA4 com VIO depositados em placa de vidro.
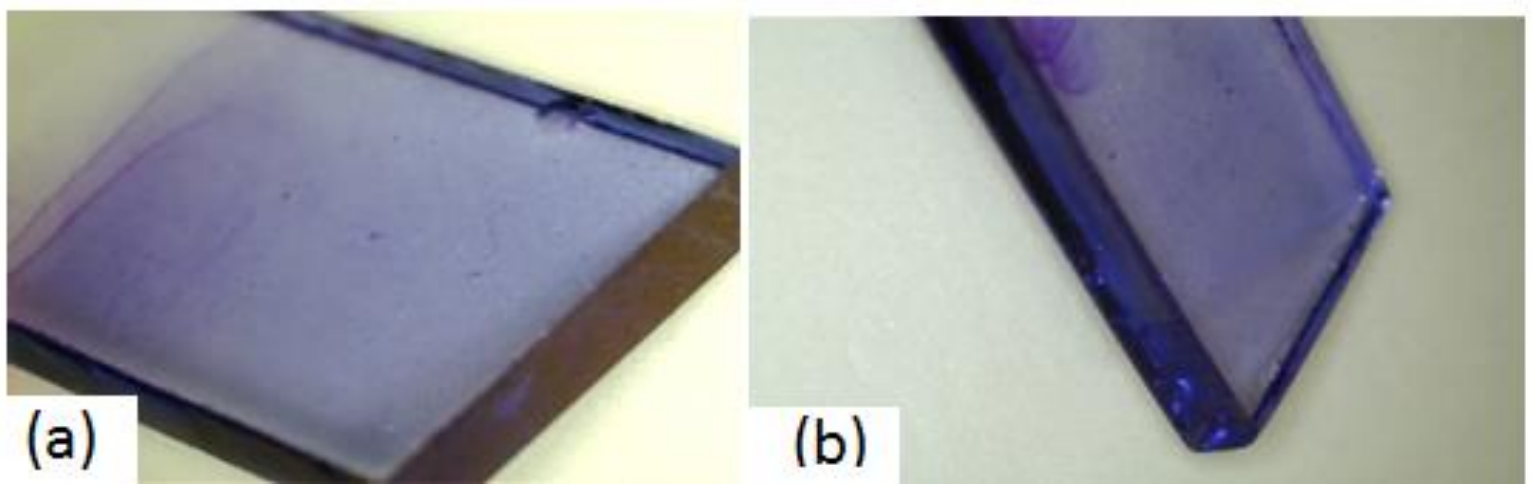

Fonte: Autoria própria. 
Figura 3. Espectro de absorção no UV-Vis do filme de PVA1/VIO em função do número de bicamadas depositadas, com ênfase na absorção do VIO.
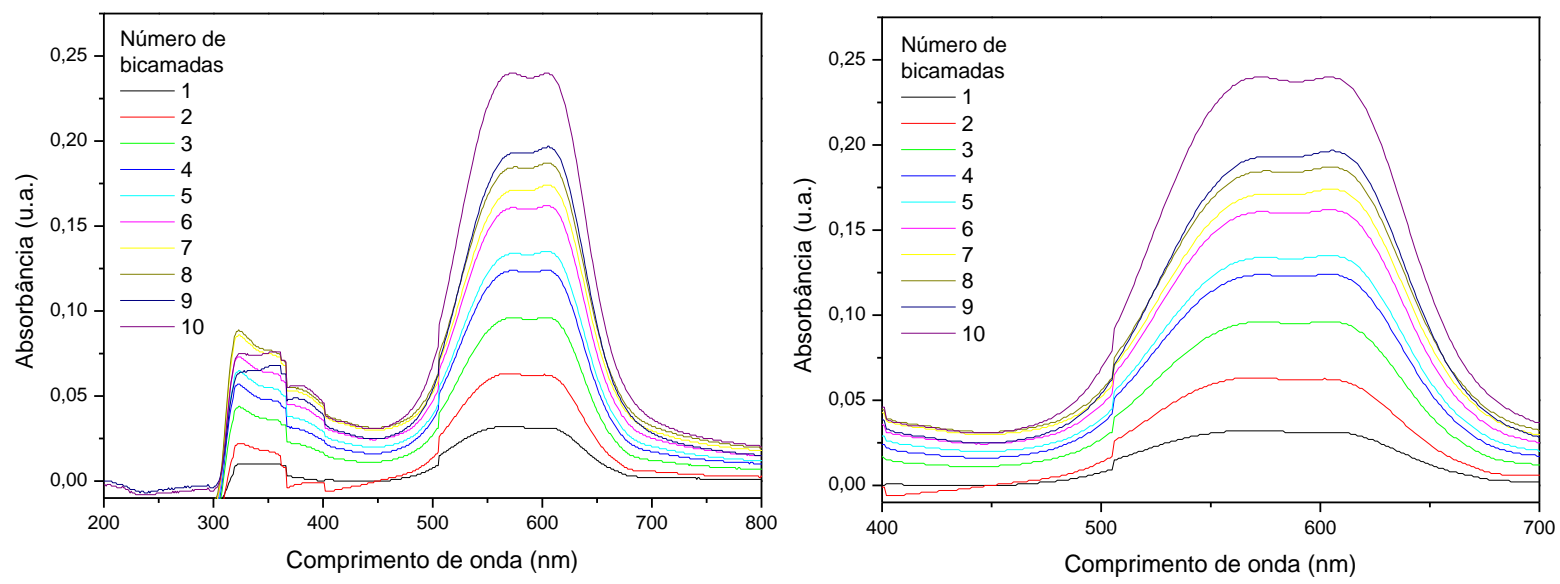

Fonte: Autoria própria.

Figura 4. Curva de crescimento do VIO nos comprimentos de onda de 571 e $603 \mathrm{~nm}$.
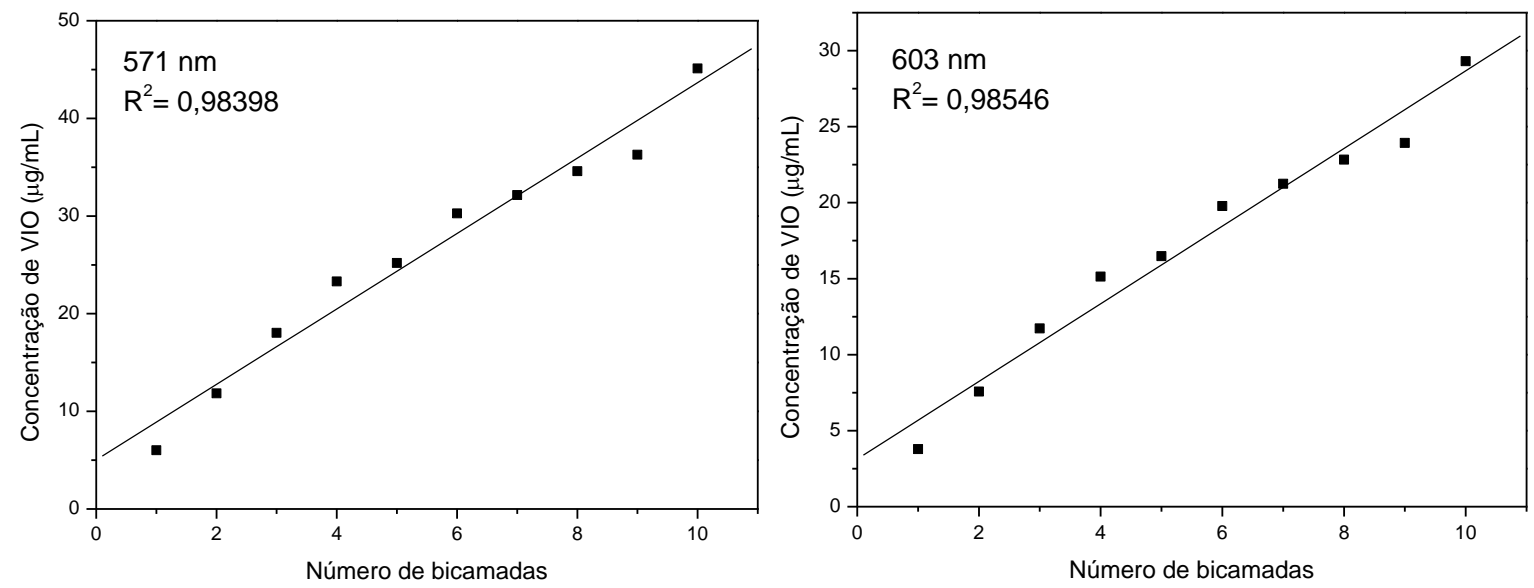

Fonte: Autoria própria.

Figura 5. Espectro de absorção no UV-Vis do filme de PVA4/VIO em função do número de bicamadas depositadas, com ênfase na absorção do VIO.
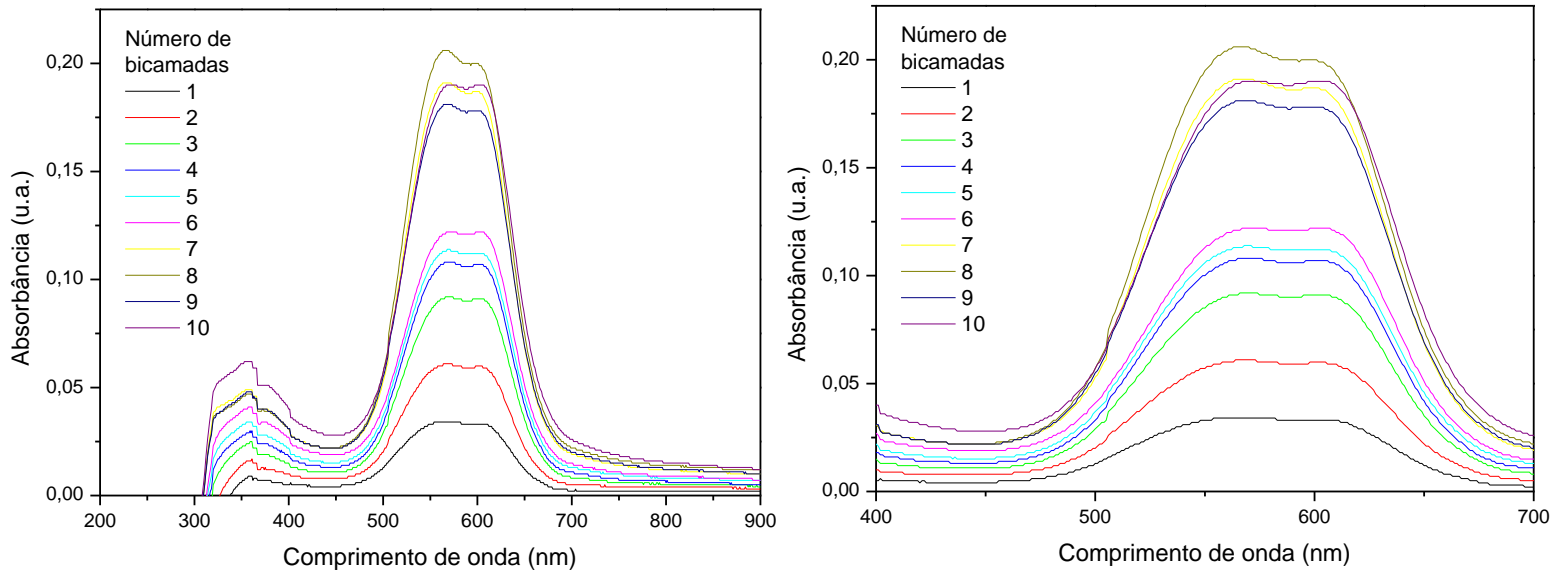

Fonte: Autoria própria. 
Figura 6. Curva de crescimento do VIO nos comprimentos de onda de 565 e $603 \mathrm{~nm}$.
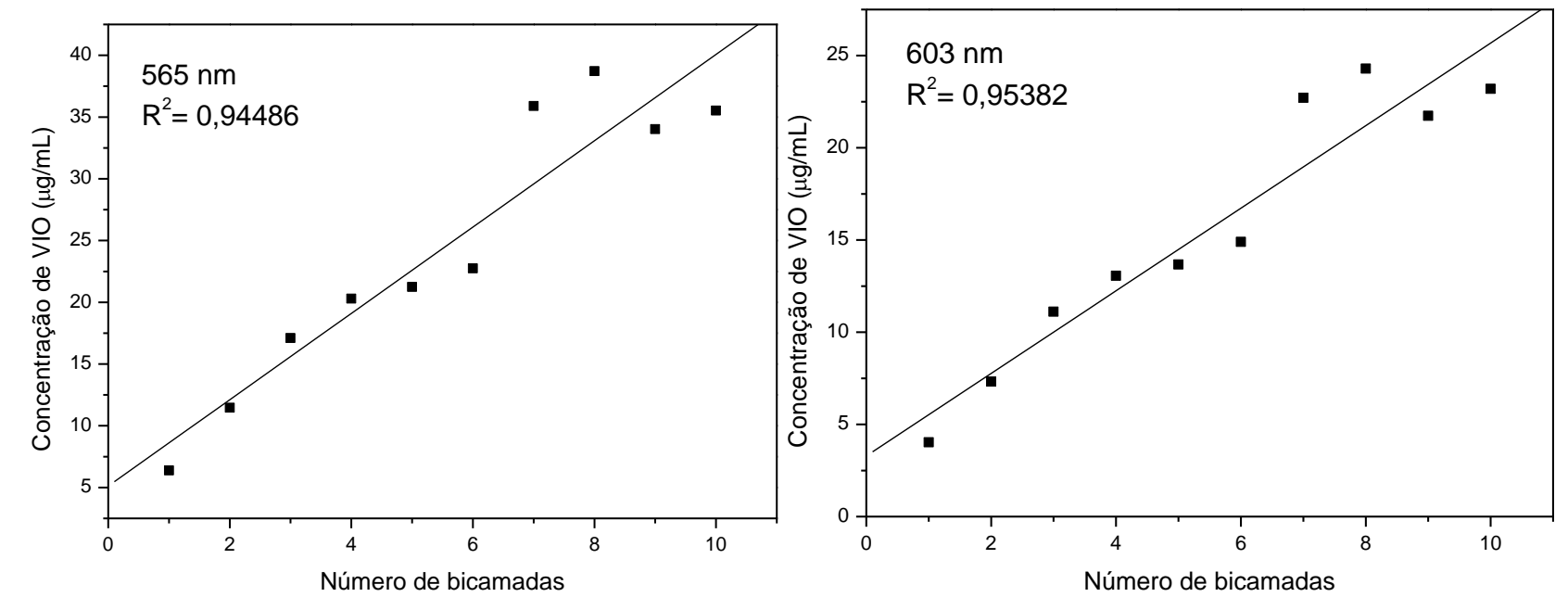

Fonte: Autoria própria.

O filme de CMC/VIO é apresentado na

Figura 7. O espectro de absorção e a curva de crescimento do filme de CMC/VIO são apresentados nas Figuras 8 e 9, respectivamente.

Figura 7. Imagens de Microscopia óptica do filme de CMC1/VIO depositado em placa de vidro.

Fonte: Autoria própria.

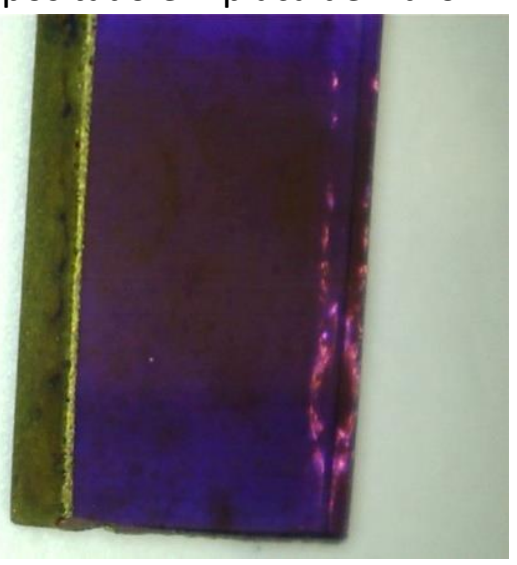

Figura 8. Espectro de absorção no UV-Vis do filme CMC1/VIO em função do número de bicamadas depositadas, com ênfase na absorção do VIO.
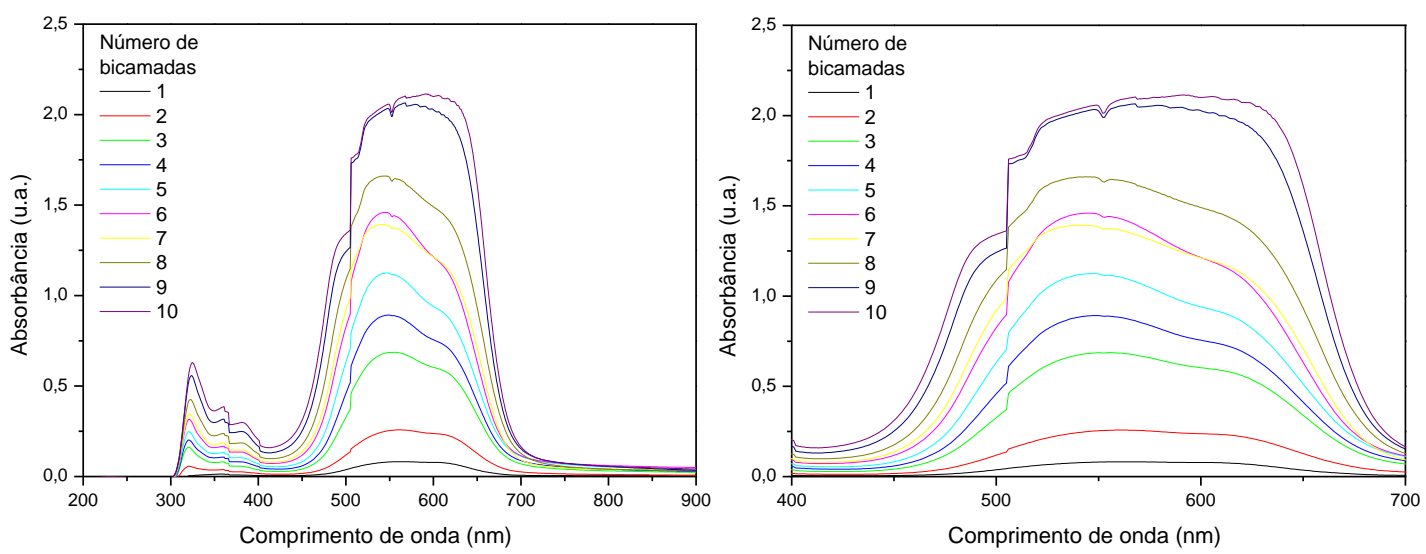

Fonte: Autoria própria. 
Figura 9. Curva de crescimento do VIO nos comprimentos de onda de 615 e $642 \mathrm{~nm}$.
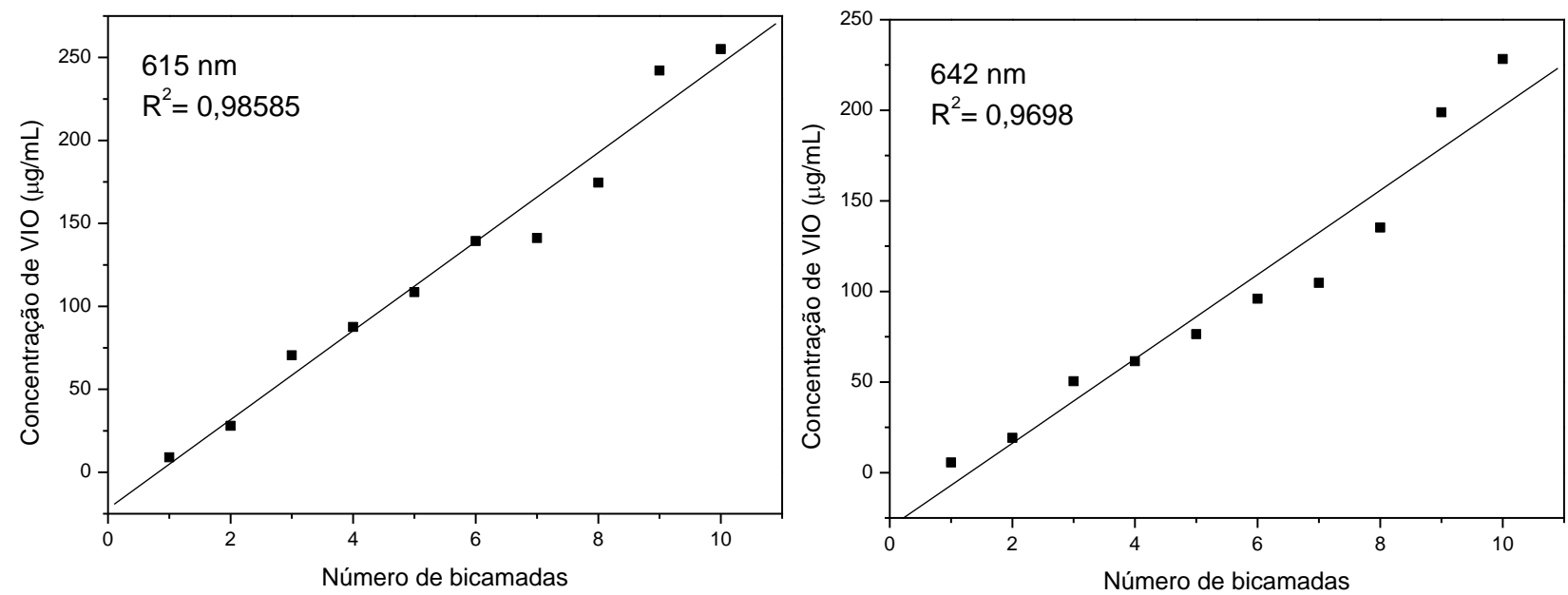

Fonte: Autoria própria.

\section{DISCUSSÃO}

O polímero PVA nas concentrações 10 mg.mL-1 e 40 mg.mL-1 obtiveram bons resultados com o composto violeta cristal (composto com carga catiônica), o que demonstra o caráter aniônico do polímero. Este fator foi evidenciado empregando-se um polímero com carga aniônica (CMC) e um composto de carga catiônica (Violeta Cristal).

Através de medidas de espectroscopia de UV-Vis, constatou-se o aumento linear da absorbância dos filmes formados, à medida que cada camada era depositada, indicando que após cada etapa, uma mesma quantidade de material foi depositada sobre a camada anterior, tendo-se, portanto, um controle da espessura.

\section{CONCLUSÃO}

Atualmente, a técnica de automontagem permite a fabricação de filmes ultrafinos a partir de diferentes tipos de materiais, de maneira rápida e barata, com um elevado controle da espessura dos filmes depositados. Os resultados obtidos foram bons, pois obteve um crescimento linear permitindo o monitoramento das camadas depositadas, bem como, apresentando eficiência para suas diferentes aplicações.

\section{REFERÊNCIAS}

ALMEIDA, L. C. P. Filmes finos multicamadas de polímeros condutores, nanotubos de carbono e fulerenos modificados para aplicação na conversão de energia solar. 2012. 154 p. Tese (Doutorado)- Campinas, 2012.

DANTAS, C. A. R. Fabricação de microcanais para integração de uma "língua eletrônica" em um sistema lab-on-a-chip. 2009. 60 p. Dissertação (Mestrado) - Sorocaba, 2009.

GREGORUT, C. Avaliação do desempenho de uma língua eletrônica na identificação de cultivares de soja. Dissertação (Mestrado) - Universidade de São Paulo, São Paulo, 2010.

LIMA, L. R. Imunossensores à base de filmes nanoestruturados de fibroína da seda - peptídeo antigênico NS5A-1- vanadato de ítrio: európio para detecção de Hepatite C. 2014. 79p. 
Dissertação (Mestrado) - Universidade Estadual Paulista "Júlio de Mesquita Filho", Araraquara, 2014.

PATERNO, L. G.; MATTOSO, L. H. C.; OLIVEIRA JR., O. N. Filmes poliméricos ultrafinos produzidos pela técnica de automontagem: preparação, propriedades e aplicações. Química Nova, v.24, n.2, p.228-235, 2001.

https://doi.org/10.1590/S0100-

$\underline{40422001000200013}$

VOLPATI, D. Filmes nanoestruturados aplicados ao sistema de língua eletrônica: um estudo de interfaces. 2012. 151p. Tese (Doutorado) Universidade Estadual Paulista "Júlio de Mesquita Filho", Presidente Prudente, 2012. 